\title{
Pien Tze Huang induces apoptosis and inhibits proliferation of 5-fluorouracil-resistant colorectal carcinoma cells via increasing miR-22 expression
}

\author{
ZHAORONG CHEN ${ }^{1 *}$, ALING SHEN $^{2 *}$, LIYA LIU $^{2}$, YOUQIN CHEN $^{3}$, JIANFENG CHU $^{2}$, \\ QIAOYAN $\mathrm{CAI}^{2}, \mathrm{FEI} \mathrm{QI}^{2}$, THOMAS JOSEPH SFERRA ${ }^{3}$ and JUN PENG ${ }^{2 *}$ \\ ${ }^{1}$ College of Pharmacy; ${ }^{2}$ Academy of Integrative Medicine, Fujian University of Traditional Chinese Medicine, \\ Fuzhou, Fujian 350122, P.R. China; ${ }^{3}$ Department of Pediatrics, Case Western Reserve University School \\ of Medicine, Cleveland, $\mathrm{OH} 44106, \mathrm{USA}$
}

Received April 17, 2016; Accepted July 1, 2017

DOI: 10.3892/etm.2017.4951

\begin{abstract}
The well-known traditional Chinese medicine formula Pien Tze Huang (PZH) has long been used to treat various malignancies, including colorectal cancer (CRC). It was recently reported that $\mathrm{PZH}$ possesses the ability to overcome multidrug resistance in CRC cells. In the present study, a 5-fluorouracil (5-FU) resistant human CRC cell line (HCT-8/5-FU) was used to further evaluate the effect of PZH on chemotherapy (chemo)-resistance and investigate the mechanisms through which this occurs. The results identified that $\mathrm{PZH}$ significantly reduced the viability and cell density of HCT-8/5-FU cells in a dose- and time-dependent manner $(\mathrm{P}<0.05)$. $\mathrm{PZH}$ inhibited cell survival, reduced the proportion of cells in S-phase, and suppressed the expression of pro-proliferative proteins cyclin D1 and cyclin-dependent kinase 4. In addition, PZH treatment induced nuclear condensation and fragmentation, activated caspase- 9 and -3 and increased the pro-apoptotic Bcl-2-associated X protein/B-cell lymphoma 2 protein ratio. Furthermore, PZH treatment upregulated the expression of microRNA-22 (miR-22) and downregulated the expression of c-Myc (a target gene of miR-22). In conclusion, the findings from the present study suggest that PZH can overcome chemo-resistance in cancer
\end{abstract}

Correspondence to: Dr Jun Peng, Academy of Integrative Medicine, Fujian University of Traditional Chinese Medicine, 1 Qiuyang Road, Shangjie, Minhou, Fuzhou, Fujian 350122, P.R. China

E-mail: pjunlab@hotmail.com

*Contributed equally

Abbreviations: CRC, colorectal cancer; MDR, multidrug resistance; PZH, Pien Tze Huang; TCM, traditional Chinese medicine

Key words: Pien Tze Huang, traditional Chinese medicine, 5-fluorouracil-resistance, colorectal neoplasm, miR-22 cells, likely through increasing miR-22 expression, and by reversing the imbalance between levels of proliferation and apoptosis.

\section{Introduction}

Colorectal cancer (CRC) is a primary public health concern, as it is the third most common cancer and a leading cause of cancer-related deaths worldwide (1). Chemotherapy is a key therapeutic modality for CRC (2). However, due to the complexity of CRC initiation and development, numerous currently-used and single-target-based chemotherapeutics result in drug resistance with long-term use, leading to treatment failure (3-6). Recently, traditional Chinese medicines (TCMs) have received great interest, due to their therapeutic efficacy and lack of side effects compared with modern chemotherapeutic agents $(7,8)$.

Moreover, TCM formulas are a complex combination of natural products, which each contain numerous chemical compounds. TCM formulas are therefore considered to be multi-targeted agents, exerting their therapeutic function in a more holistic way $(9,10)$. Thus, discovering novel anti-tumor agents in TCMs may be beneficial in overcoming chemotherapy (chemo)-resistance.

MicroRNAs (miRNAs) are a class of endogenous, short and non-coding RNAs, which are thought to function as oncogenes or tumor suppressors, via negatively regulating target gene expression $(11,12)$. Accumulating evidence indicates that miRNAs serve essential roles in multiple oncogenic cellular processes, such as cell survival, proliferation, metastasis and drug resistance (13-18). miRNA-22 (miR-22) has been proposed to act as a tumor suppressor, and is downregulated in a variety of tumors (19-24). miR-22 exerts its tumor-suppressive activities primarily through repressing the expression of key target genes, such as c-Myc $(25,26)$. Notably, the expression of miR-22 itself is negatively regulated by c-Myc, creating a double negative feedback loop (27). The proto-oncogene c-Myc is a transcription factor that activates the expression of genes involved in numerous biological effects, including promoting the proliferation of cancer cells $(28,29)$. Overexpression of 
c-Myc is found in numerous cancer types (30), in which it promotes cell proliferation and inhibits apoptosis by modifying the expression of target genes [such as cyclin D1 and B-cell lymphoma 2 (Bcl-2)], facilitating carcinogenesis $(31,32)$ and inducing drug resistance (33-35). Therefore, reversing the imbalance of cell proliferation/apoptosis in cancer cells through targeting the miR-22/c-Myc feedback network may be a promising strategy in overcoming cancer drug resistance.

Pien Tze Huang (PZH) is a well-known TCM formula, that was first described in 1,555 AD in the Chinese Ming Dynasty (36). PZH has long been used clinically in China to treat various types of cancer. Previous studies have proposed that $\mathrm{PZH}$ displays this broad range of antitumor effects by targeting multiple cellular processes (37-46). It has recently been demonstrated that $\mathrm{PZH}$ possesses the ability to overcome multidrug resistance in CRC cells (47). In the present study, the effect of PZH on chemo-resistance was further evaluated and the possible molecular mechanisms underlying this effect were investigated. To explore this, 5-fluorouracil (5-FU)-resistant CRC cells were used to identify the effects of PZH on cell proliferation/apoptosis and the miR-22/c-Myc signaling network.

\section{Materials and methods}

Materials and reagents. Roswell Park Memorial Institute (RPMI)-1640 medium, fetal bovine serum (FBS), penicillin, streptomycin and trypsin-EDTA were purchased from Thermo Fisher Scientific, Inc. (Waltham, MA, USA). The BD Cycletest Plus DNA reagent kit (cat no. 340242) was purchased from BD Biosciences (San Jose, CA, USA). The colorimetric assay kits for caspase-3 (cat no. KGA204) and caspase-9 (cat no. KGA404) were purchased from Nanjing KeyGen Biotech. Co., Ltd. (Nanjing, China). The Hoechst staining kit (cat no. C0003) was obtained from Beyotime Institute of Biotechnology (Shanghai, China). Rabbit polyclonal Bcl-2 antibody (cat no. 4223), polyclonal Bcl-2-associated X protein (Bax) antibody (cat no. 5023), monoclonal CDK4 antibody (cat no. 12790), monoclonal cyclin D1 antibody (cat no. 2978), monoclonal c-Myc antibody (cat no. 13987) and monoclonal $\beta$-actin antibody (cat no. 4970) and anti-rabbit IgG, HRP-linked Antibody (cat no. 7074) were obtained from Cell Signaling Technology, Inc. (Beverly, MA, USA). RNA extraction reagents kits RNAiso Plus (for total RNA; cat no. 9108) and RNAiso (for small RNA; cat no. 9753A), PrimeScript RT reagent kit (for RT-PCR; cat no. DRR037A), PCR Master Mix kit (for RT-PCR; cat no. RR300A), cDNA Synthesis kit (for miRNA; cat no. 203301) and SYBR PrimeScript miRNA RT-PCR kit (for miRNA; cat no. RR716) were provided by Takara Biotechnology Co., Ltd. (Dalian, China). All other chemicals, unless otherwise stated, were obtained from Sigma-Aldrich (Merck Millipore, Darmstadt, Germany).

Preparation of PZH and 5-FU. PZH was obtained from and authenticated by Zhangzhou Pien Tze Huang Pharmaceutical Co., Ltd. (China Food and Drug Administration approval no. Z35020242; Zhangzhou, China). A stock solution of $\mathrm{PZH}$ was prepared prior to use by dissolving the $\mathrm{PZH}$ power in phosphate-buffered saline (PBS) to a concentration of $20 \mathrm{mg} / \mathrm{ml}$. Diluting the stock solution in the culture medium provided the working concentrations of $\mathrm{PZH}(0,0.25,0.5$ or $0.75 \mathrm{mg} / \mathrm{ml}$ ). 5-FU was purchased from Sigma-Aldrich. For cell-based experiments, a stock solution of 5-FU was prepared by dissolving 5-FU powder in dimethyl sulfoxide (DMSO) to a concentration of $1 \mathrm{~mol} / \mathrm{l}$. Diluting the stock solution in the culture medium provided the working concentrations of 5-FU $(0,0.25,0.5,1,2,4$ or $8 \mathrm{mmol} / \mathrm{l})$.

Cell culture. Human CRC HCT-8 cells and 5-FU resistant HCT-8/5-FU cells were obtained from Nanjing KeyGen Biotech. Co., Ltd. Cells were grown in RPMI-1640 medium, supplemented with $10 \% \mathrm{FBS}, 100 \mathrm{U} / \mathrm{ml}$ penicillin and $100 \mu \mathrm{g} / \mathrm{ml}$ streptomycin. In addition, HCT-8/5-FU cell cultures were supplemented with $15 \mu \mathrm{g} / \mathrm{ml} 5$-FU. Cells were cultured at $37^{\circ} \mathrm{C}$ and $5 \% \mathrm{CO}_{2}$ in a humidified incubator. The cells were subcultured at a ratio of 1:4-1:6 at between 80 and $90 \%$ confluency.

Evaluation of cell viability by the MTT assay. Cell viability was assessed by the MTT colorimetric assay (cat no. M8180; Solarbio, Beijing, China). HCT-8 cells or HCT-8/5-FU cells were seeded into 96 -well plates at a density of $0.8 \times 10^{4}$ cells/well in $0.1 \mathrm{ml}$ medium. The HCT- 8 and HCT-8/5-FU cells were then treated with various concentrations of 5 -FU $(0,0.25$, $0.5,1,2,4$ and $8 \mathrm{mmol} / \mathrm{l}$ ) for $48 \mathrm{~h}$, while HCT-8/5-FU cells were treated with different concentrations of PZH $(0,0.25$, 0.5 and $0.75 \mathrm{mg} / \mathrm{ml}$ ) for 24,48 and $72 \mathrm{~h}$. Following treatment, $0.5 \mathrm{mg} / \mathrm{ml}$ of MTT in $100 \mu \mathrm{l}$ PBS was added to each well and the samples were incubated for an additional $4 \mathrm{~h}$ at $37^{\circ} \mathrm{C}$. The purple-blue MTT formazan precipitate that formed was then collected and dissolved in $100 \mu \mathrm{l}$ DMSO. The absorbance of the solution was measured at $570 \mathrm{~nm}$ using a plate reader (ELx800; BioTek, Winooski, VT, USA).

Observation of morphological changes. HCT-8/5-FU cells were seeded into 6 -well plates at a density of $2 \times 10^{5}$ cells/well in $2 \mathrm{ml}$ medium. The cells were then treated with various concentrations of PZH (as previously described) for $24 \mathrm{~h}$. Cell morphology was observed using a phase-contrast microscope (Leica Microsystems GmbH, Wetzlar, Germany) and images were captured at a magnification of $\mathrm{x} 200$.

Cell cycle analysis. Cell cycle analysis was performed by fluorescence-activated cell sorting (FACS) using FACSCalibur (BD Biosciences) and propidium iodide (PI) staining. Following treatment with a number of concentrations $(0,0.25$, 0.5 and $0.75 \mathrm{mg} / \mathrm{ml}$ ) of PZH for $24 \mathrm{~h}, \mathrm{HCT}-8 / 5-\mathrm{FU}$ cells were harvested, adjusted to a concentration of $1 \times 10^{6}$ cells $/ \mathrm{ml}$ and fixed in $70 \%$ ethanol at $4^{\circ} \mathrm{C}$ overnight. The fixed cells were washed twice with cold PBS and then incubated for $30 \mathrm{~min}$ with RNase $(8 \mu \mathrm{g} / \mathrm{ml})$ and PI $(10 \mu \mathrm{g} / \mathrm{ml})$. The fluorescent signal was detected through an FL2 channel (488 nm laser excitation) and the proportion of DNA in different phases of the cell cycle was analyzed using Modfit LT software (version 3.0; Verity Software House, Topsham, ME, USA).

Colony formation assay. HCT-8/5-FU cells were seeded into 6 -well plates at a density of $2 \times 10^{5}$ cells/well and treated with a number of concentrations $(0,0.25,0.5$ and $0.75 \mathrm{mg} / \mathrm{ml})$ of $\mathrm{PZH}$ for $24 \mathrm{~h}$. The cells were then harvested, diluted with fresh 
media in the absence of $\mathrm{PZH}$ and reseeded into 6-well plates at a density of $1 \times 10^{3}$ cells/well. Following incubation for between 7 and 8 days in a $37^{\circ} \mathrm{C}$ humidified incubator with $5 \% \mathrm{CO}_{2}$, colonies were stained with crystal violet. Images were then captured, where the number of stained colonies represented the survival of HCT-8/5-FU cells.

Detection of apoptosis with Hoechst staining.HCT-8/5-FU cells were seeded into 12 -well plates at a density of $1 \times 10^{5}$ cells/well in $1 \mathrm{ml}$ medium. Following treatment with $\mathrm{PZH}$ as described above for $24 \mathrm{~h}$, levels of apoptosis were determined using the Hoechst staining kit according to the manufacturer's instruction. Briefly, cells were fixed with $4 \%$ polyoxymethylene and then incubated in Hoechst solution for between 5 and $10 \mathrm{~min}$ in the dark. Images of the staining images were captured using a phase-contrast fluorescent microscope (Leica Microsystems $\mathrm{GmbH})$ at a magnification of $\mathrm{x} 400$.

Analysis of caspase activation. The activity of caspase-9 and -3 was determined using colorimetric assay kits following the manufacturer's instructions. Briefly, following treatment with various concentrations of PZH as described above for $24 \mathrm{~h}$, HCT-8/5-FU cells were lysed with lysis buffer (provided in the kit) for $30 \mathrm{~min}$ on ice. The lysed cells were centrifuged at $14,000 \mathrm{x} \mathrm{g}$ for $10 \mathrm{~min}$, and $100 \mu \mathrm{g}$ of the protein obtained was incubated with $50 \mu 1$ Asp-Glu-Val-Asp (DEVD)-peptide nucleic acid (pNA; a specific substrate of caspase-3) or Leu-Glu-His-Asp (LEHD)-pNA (a specific substrate of caspase-9) at $37^{\circ} \mathrm{C}$ in the dark for $2 \mathrm{~h}$. The absorbance of samples was measured at $405 \mathrm{~nm}$ using an ELISA plate reader (BioTek). The data were normalized to the caspase activity measured in control (untreated) cells) and represented as fold-change vs. control.

Total RNA extraction and RT-PCR. HCT-8/5-FU cells were seeded into 6 -well plates at a density of $2 \times 10^{5}$ cells/well in $2 \mathrm{ml}$ medium. The cells were then treated with a number of concentrations of PZH as described above for $24 \mathrm{~h}$. Total RNA was isolated using the RNAiso Plus reagent kit, according to the manufacturers instructions. Then, $1 \mu \mathrm{g}$ total RNA was reverse transcribed with the PrimeScript RT reagent kit, following the manufacturer's instructions. The complementary DNA (cDNA) obtained was then used to determine the quantity of Bcl-2, Bax, CDK4, cyclin D1 and c-Myc mRNA by PCR using the PCR Master Mix kit. PCR was carried out under the following conditions: Denaturation at $95^{\circ} \mathrm{C}$ for $3 \mathrm{~min}$, followed by 30 cycles of denaturation at $94^{\circ} \mathrm{C}$ for $40 \mathrm{sec}$, annealing at $60^{\circ} \mathrm{C}$ for $40 \mathrm{sec}$, and primer extension at $72^{\circ} \mathrm{C}$ for $45 \mathrm{sec}$. A final extension was performed at $72^{\circ} \mathrm{C}$ for $10 \mathrm{~min}$. GAPDH was used as an internal control. Samples were analyzed by gel electrophoresis (1.5\% agarose). The DNA bands were examined using a Gel Documentation system (Gel Doc 2000; Bio-Rad Laboratories, Inc., Hercules, CA, USA). The sequences of the primers used for amplification of the transcripts are described in Table I.

Western blot analysis. HCT-8/5-FU cells were seeded into culture flasks at a density of $1 \times 10^{6}$ in $5 \mathrm{ml}$ medium and treated with various concentrations of $\mathrm{PZH}$ as described above for $24 \mathrm{~h}$. Following treatment, cells were lysed with
Table I. Primer sequences for reverse transcription polymerase chain reaction.

\begin{tabular}{ll}
\hline Gene & \multicolumn{1}{c}{ Primer sequences } \\
\hline GAPDH & F:5'-CGACCACTTTGTCAAGCTCA-3' \\
& R:5'-AGGGGTCTACATGGCAACTG-3' \\
Bcl-2 & F:5'-CAGCTGCACCTGACGCCCTT-3' \\
& R:5'-GCCTCCGTTATCCTGGAT CC-3' \\
Bax & F:5'-TGCTTCAGGGTTTCATCCAGG-3' \\
& R:5'-TGGCA AAGTAGAAAAGGGCGA-3' \\
Cyclin D1 & F:5'-CATGTAGACCAGGACCTAAGC-3' \\
& R:5'-AACTGGCGCATCAGATCCTAG-3' \\
CDK4 & F:5'-GTAAAGCTGGAAAGGGACGAAC-3' \\
& R:5'-ACACAGGTAACGGCTGAGGGAA-3' \\
c-Myc & F:5'-CACACATCAGCACAACTACGCA-3' \\
& R:5'-TTGACCCTCTTGGCAGCAG-3'
\end{tabular}

Bcl-2, B-cell lymphoma 2; Bax, Bcl-2-associated X protein; CDK4, cyclin-dependent kinase 4 ; F, forward; $\mathrm{R}$, reverse.

RIPA Lysis and Extraction buffer (cat no. 89900; Thermo Fisher Scientific, Inc.) containing protease (cat no. 535142; Calbiochem; EMD Millipore, Billerica, MA, USA) and phosphatase inhibitor cocktails (cat no. J61022; Thermo Fisher Scientific, Inc.), and the lysates were centrifuged at $14,000 \mathrm{x} \mathrm{g}$ for $20 \mathrm{~min}$. Then, $50 \mu \mathrm{g}$ protein was separated using $12 \%$ SDS-PAGE gels for $2 \mathrm{~h}$ at $80 \mathrm{~V}$. The proteins were then transferred onto polyvinylidene fluoride membranes. Membranes were then blocked for $2 \mathrm{~h}$ with blocking solution (cat no. P0023B; Nanjing KeyGen Biotech. Co., Ltd.) at room temperature, washed in Tris-buffered saline with $0.25 \%$ Tween-20 (TBS-T) and exposed to primary antibodies against Bcl-2, Bax, CDK4, cyclin D1, c-Myc or $\beta$-actin $(1: 1,000)$ overnight at $4^{\circ} \mathrm{C}$. $\beta$-actin was used as an internal control for protein loading. Following this, membranes were washed with TBS-T and secondary HRP-conjugated antibody (1:2,000; anti-rabbit) was added for $1 \mathrm{~h}$ at room temperature. The membranes were then washed again with TBS-T, followed by enhanced chemiluminescence detection using SuperSignal ${ }^{\text {TM }}$ West Dura Extended Duration Substrate (cat no. 34076; Thermo Fisher Scientific, Inc.). Images were captured and analyzed using the ChemiDoc XRS+ imaging system (Bio-Rad Laboratories, Inc.).

$R T-q P C R$ analysis for the expression of miR-22. Total small RNA (sRNA) was isolated with the RNAiso reagent for small RNA following the manufacturer's instructions. Total sRNA (500 ng) was reverse transcribed with the cDNA Synthesis kit (for miRNA) according to the manufacturer's instructions. The cDNA obtained was used to determine the quantity of miR-22, with the non-coding small nuclear RNA U6 used as an internal control. The primers for miR-22 (5'-GGTAGGCTTGAAGAACTGTAAA-3') and U6 (cat no. D356-03) were obtained from Takara Biotechnology Co., Ltd. RT-qPCR was performed using SYBR PrimeScript miRNA RT-PCR kit in an Applied Biosystems 7500 Fast 

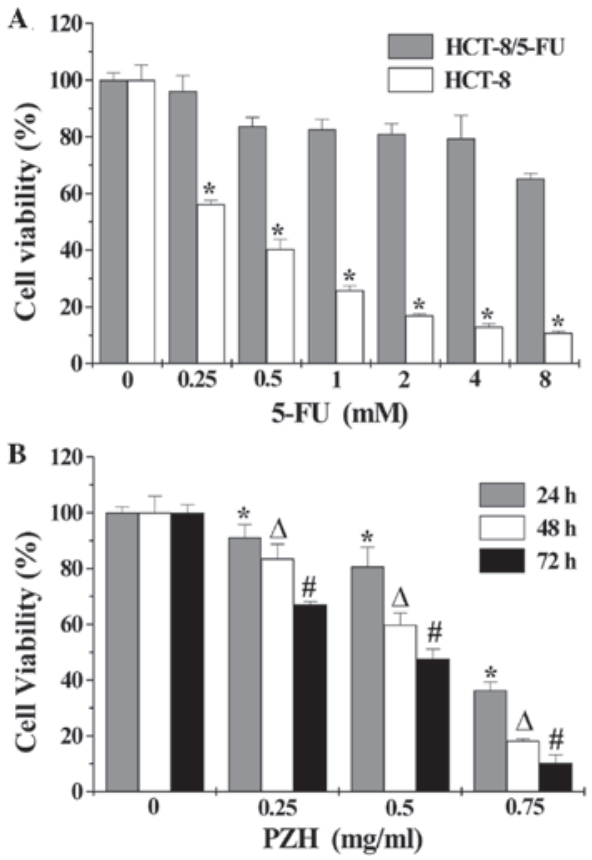

Figure 1. Effect of 5-FU and PZH on HCT-8 cell and/or HCT-8/5-FU cell viability. (A) HCT-8 and HCT-8/5-FU cell viability following treatment with 5-FU for 48 h. ${ }^{*} \mathrm{P}<0.05$ vs. control. (B) HCT-8/5-FU cell viability following treatment with $\mathrm{PZH}$ for 24,48 or $72 \mathrm{~h} .{ }^{*} \mathrm{P}<0.05$ vs. control $24 \mathrm{~h}$ group, ${ }^{\mathrm{A}} \mathrm{P}<0.05$ vs. control $48 \mathrm{~h}$ group and ${ }^{\#} \mathrm{P}<0.05$ vs. control $72 \mathrm{~h}$ group. Cell viability was determined by MTT assay following treatment with 5-FU or PZH. Results were normalized to the viability of control cells. The results are mean values with error bars of the standard deviation from at least three independent experiments. 5-FU, 5-fluorouracil; PZH, Pien Tze Huang; HCT-8, human colorectal cancer cells; HCT-8/5-FU, human colorectal cancer cells resistant to 5 -FU.

instrument (Thermo Fisher Scientific, Inc.), according to the manufacturer's protocol. miRNA expression values were determined as $\Delta \mathrm{Cq}=\mathrm{Cq}$ (sample)-Cq (U6), and relative quantities between different samples were determined as $\Delta \Delta \mathrm{Cq}=\Delta \mathrm{Cq}$ (sample 1) $-\Delta \mathrm{Cq}$ (sample 2). The values were expressed as $2^{-\Delta \Delta C q}(48)$. All RT-qPCR reactions were conducted in triplicate.

Statistical analysis. Data was analyzed using SPSS software (version 18.0; SPSS, Inc., Chicago, IL, USA). Statistical analysis of the data was performed by Student's t-tests or one-way analysis of variance. $\mathrm{P}<0.05$ was considered to indicate a statistically significant difference.

\section{Results}

HCT-8/5-FU cells are resistant to 5-FU treatment. To evaluate drug resistance in cancer cells, human CRC cells (HCT-8) and 5-FU resistant CRC cells (HCT-8/5-FU) were exposed to a number of concentrations of 5-FU and the MTT assay was performed to determine cell viability. With the 5-FU (0.25-8 mmol/l) treatment, the viability of HCT- 8 cells was significantly decreased by $43.8-89.2 \%$ ( $\mathrm{P}<0.05$ vs. untreated control), whereas HCT-8/5-FU cell viability was not significantly decreased (reductions of 3.9-34.8\% were observed), suggesting that HCT-8/5-FU cells were resistant to 5-FU treatment (Fig. 1A).
PZH inhibits the proliferation of HCT-8/5-FU cells. The effect of PZH on the proliferation of HCT-8/5-FU cells was evaluated using the MTT assay. Treatment with PZH significantly decreased HCT-8/5-FU cell viability in a dose- and time-dependent manner ( $\mathrm{P}<0.05$; Fig. 1B). In order to confirm this effect of $\mathrm{PZH}$, cell density was observed using phase-contrast microscopy, which identified that PZH treatment decreased HCT-8/5-FU cell confluence in a dose-dependent manner (Fig. 2A). In addition, cell cycle analysis was performed, which determined that PZH treatment $(0.5$ and $0.75 \mathrm{mg} / \mathrm{ml})$ decreased the percentage of cells in the S phase (15.99 and $15.73 \%$, respectively) compared with that for untreated cells (37.07\%), but increased the percentage of cells in the $\mathrm{G}_{0} / \mathrm{G}_{1}$ phase (67.68 and $70.51 \%$, respectively) compared with $41.84 \%$ for the untreated cells, indicating that the inhibitory effect of PZH on HCT-8/5-FU cell proliferation is associated with the arrest of $\mathrm{G}_{1} / \mathrm{S}$ cell cycle progression (Fig. 2B). Furthermore, the effect of PZH on HCT-8/5-FU cell survival was examined using a colony formation assay, which showed PZH treatment markedly inhibited the survival of HCT-8/5-FU cells (Fig. 2C). Collectively, this data demonstrates that PZH inhibits the proliferation of HCT-8/5-FU cells.

PZH induces HCT-8/5-FU cell apoptosis. Cell apoptosis was assessed by observation of nuclear morphological changes via staining the cell nuclei with Hoechst DNA-binding dye. PZH-treated cells showed the condensed chromatin and fragmented nuclei typical of apoptosis, whereas the nuclei of the untreated cells were homogenously stained showing intact nuclei, suggesting that $\mathrm{PZH}$ promotes apoptosis of HCT-8/5-FU cells (Fig. 3A). To identify the downstream effectors in this apoptotic signaling pathway, the activation of caspase- 9 and -3 was examined by a colorimetric assay using specific substrates, DEVD-pNA and LEHD-pDA. Treatment with 0.5 and $0.75 \mathrm{mg} / \mathrm{ml}$ PZH significantly induced activation of caspase- 9 in HCT-8/5-FU cells $(\mathrm{P}<0.05$; Fig. 3B). Furthermore, $0.25-0.75 \mathrm{mg} / \mathrm{ml} \mathrm{PZH} \mathrm{significantly} \mathrm{induced}$ activation of caspase- 3 ( $\mathrm{P}<0.05$; Fig. 3C).

PZH regulates the expression of miR-22 and c-Myc. RT-qPCR was performed to determine the expression of miR-22. As shown in Fig. 4A, the expression of miR-22 in HCT-8/5-FU cells was significantly upregulated by $\mathrm{PZH}$ treatment in a dose-dependent manner $(\mathrm{P}<0.05)$. In addition, RT-PCR (Fig. 4B) and western blot analysis (Fig. 4C) indicated that PZH treatment profoundly decreased the mRNA and protein expression of c-Myc in HCT-8/5-FU cells.

$P Z H$ regulates the expression of $B c l-2, B a x$, cyclin DI and $C D K 4$. RT-PCR and western blotting were performed to examine the mRNA and protein expression levels of Bcl-2, Bax, cyclin D1 and CDK4. PZH treatment markedly reduced the expression of $\mathrm{Bcl}-2$, cyclin D1 and CDK4, and increased the expression of Bax, at both the transcriptional and translational levels in HCT-8/5-FU cells following PZH treatment (Fig. 4B and C).

\section{Discussion}

Drug resistance and toxicity limit the effectiveness of the chemotherapeutic regimens currently used for numerous 
A
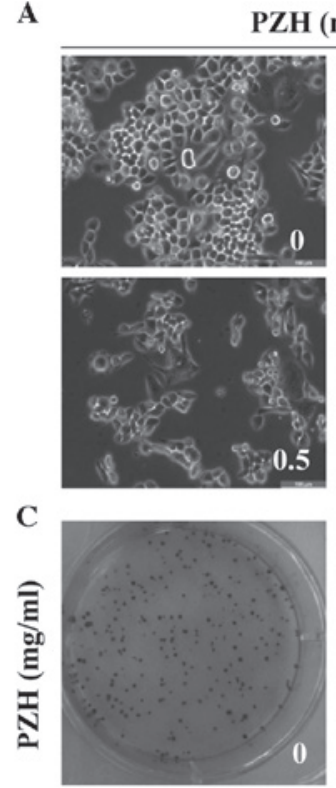

$\mathrm{PZH}(\mathrm{mg} / \mathrm{ml})$
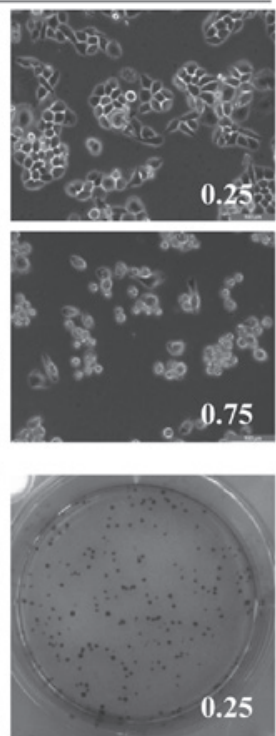

B
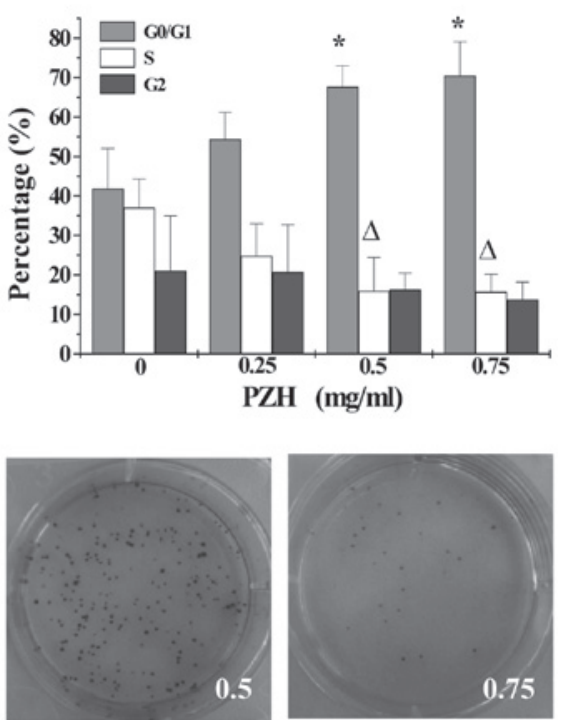

Figure 2. Effect of PZH on HCT-8/5-FU cell proliferation. (A) Morphology of HCT-8/5-FU cells following treatment with PZH for 24 h, observed using a phase-contrast microscope. Images were captured at a magnification of $x 200$ and are representative of three independent experiments. (B) Fluorescence-activated cell sorting analysis of HCT-8/5-FU cells stained with propidium iodide following treatment with $\mathrm{PZH}$ for $24 \mathrm{~h} .{ }^{*} \mathrm{P}<0.05$ vs. control $\mathrm{G}_{0} / \mathrm{G}_{1}$ group, ${ }^{\Delta} \mathrm{P}<0.05$ vs. control S-phase group. The results are mean values with error bars of the standard deviation from three independent experiments. (C) Colony formation assay images of HCT-8/5-FU cells treated with PZH for 24 h. PZH, Pien Tze Huang; HCT-8/5-FU, human colorectal cancer cells resistant to 5-fluorouracil.

A

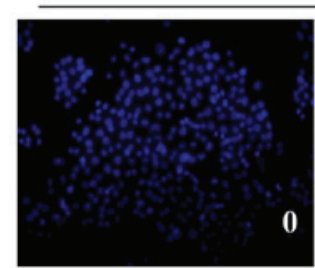

0

B

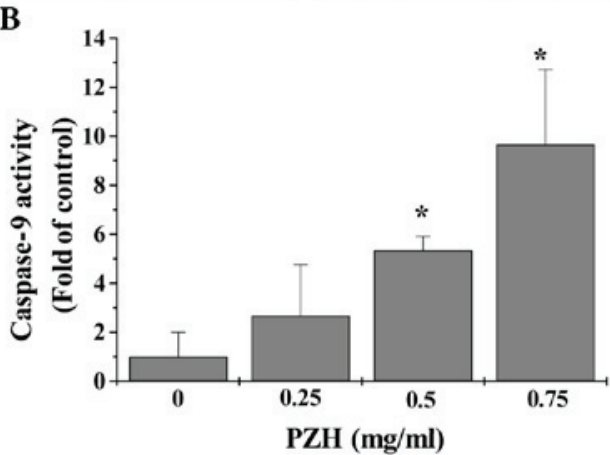

PZH (mg/ml)

\section{PZH (mgl)}
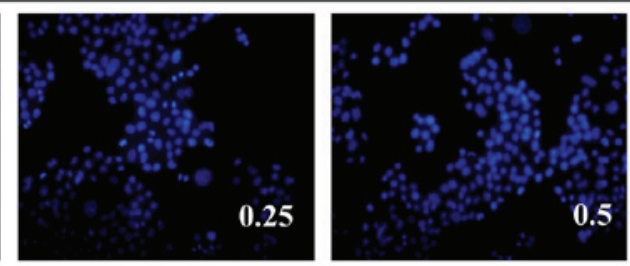

C

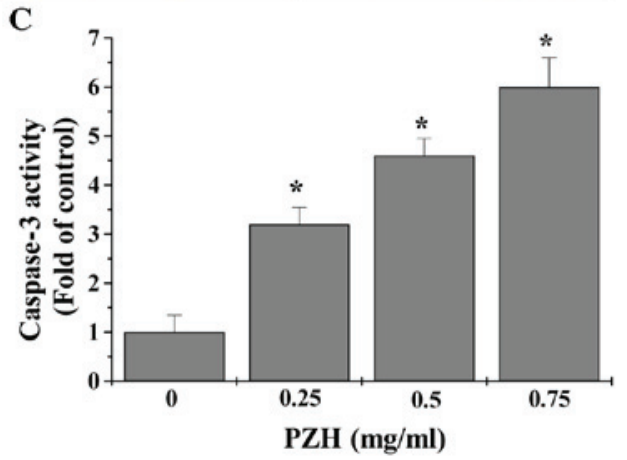

Figure 3. Effect of PZH on HCT-8/5-FU cell apoptosis. (A) Hoechst staining of HCT-8/5-FU cell nuclei following treatment with PZH for 24 h observed using a phase-contrast fluorescent microscope. Images were captured at a magnification of $x 400$ and are representative of three independent experiments. (B) Caspase-9 and (C) caspase-3 activity in HCT-8/5-FU cells following treatment with PZH for $24 \mathrm{~h}$. Activity was examined by a colorimetric assay using specific substrates of caspase- 9 and -3 , respectively. The results are mean values with error bars of the standard deviation from at least three independent experiments. ${ }^{*} \mathrm{P}<0.05$ vs. control. PZH, Pien Tze Huang.

human malignancies $(6,49,50)$. Thus, the development of safer therapeutic agents, with the ability to overcome drug resistance is a promising strategy to improve the effectiveness of cancer therapies. TCMs have received recent interest in this regard, as they have relatively few side effects and have been used for thousands of years as alternative remedies for a number of diseases, including cancer $(7,8)$. The well-known TCM formula PZH has long been used in China to treat a number of cancers $(45,51,52)$.
It has been demonstrated that PZH affects multiple targets to exert a range of antitumor activities, including the ability to reverse multidrug resistance in CRC cells (37-47), suggesting that PZH could be a novel multi-targeting therapeutic agent with the potential to overcome chemo-resistance. The present study further evaluated the inhibitory activity of PZH on chemo-resistance using 5-FU-resistant CRC cells (HCT-8/5-FU cells). The results of the MTT assay and 

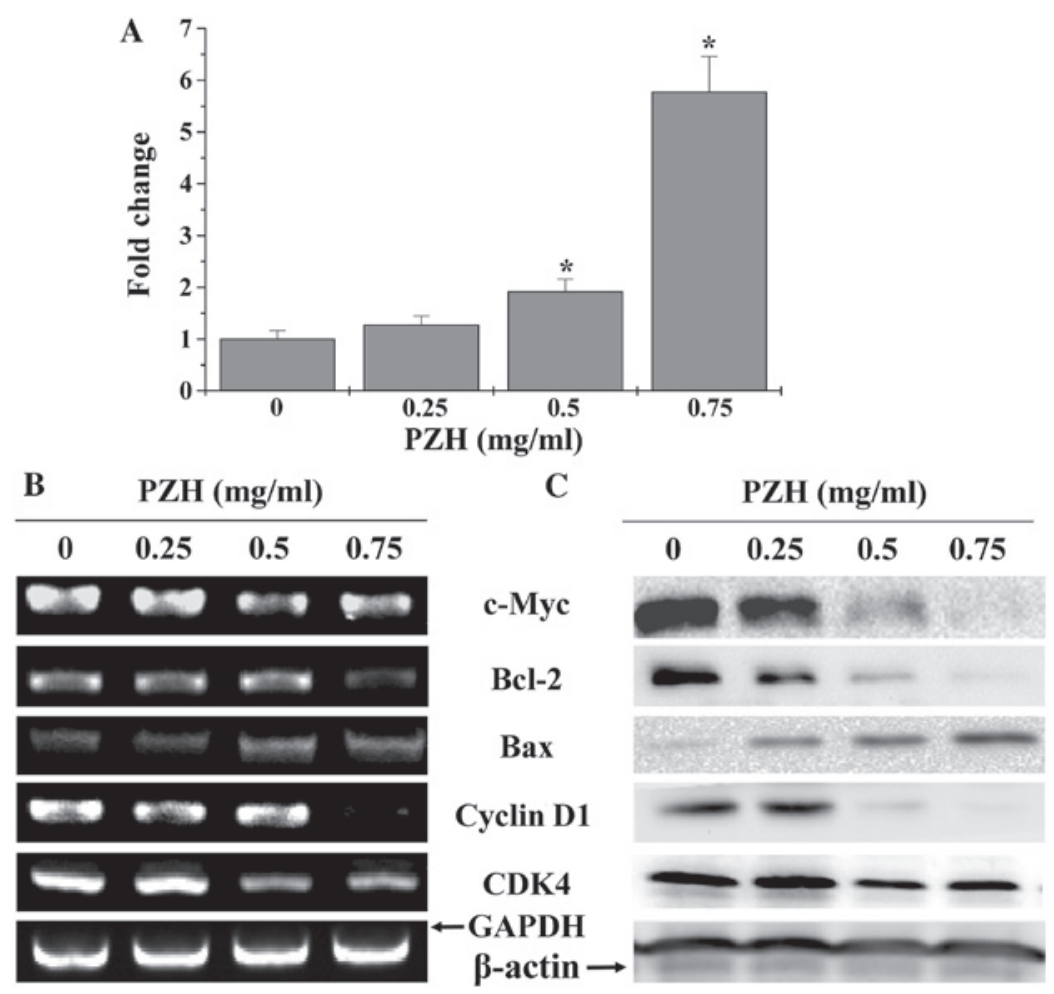

Figure 4. Effect of PZH on the expression of miR-22 and proliferation- or apoptosis-associated genes in HCT-8/5-FU cells. (A) Expression of miR-22 in HCT-8/5-FU cells following treatment with PZH for $24 \mathrm{~h}$ determined by RT-qPCR analysis. U6 was used as an internal control. The results are mean values with error bars of the standard deviation from at least three independent experiments. ${ }^{*} \mathrm{P}<0.05$ vs. control group. (B) PCR of cDNA to determine mRNA expression levels and (C) western blotting to determine protein expression levels of c-Myc, Bcl-2, Bax, Cyclin D1 and CDK4 in HCT-8/5-FU cells, following treatment with PZH for $24 \mathrm{~h}$. GAPDH and $\beta$-actin were used as internal controls for RT-PCR and western blots, respectively. Images are representative of three independent experiments. PZH, Pien Tze Huang; RT-PCR, reverse transcription polymerase chain reaction; Bcl-2, B-cell lymphoma 2; Bax, Bcl-2-associated $\mathrm{X}$ protein; CDK4, cyclin-dependent kinase 4.

cell density observations indicated that HCT-8/5-FU cells displayed significant resistance to 5-FU, but were sensitive to PZH treatment, confirming that PZH possesses the capacity to surmount chemo-resistance.

The process of drug resistance is tightly regulated by multiple factors, including miR-22 and c-Myc (16,19,33-35). As a tumor suppressor, miR-22 exerts its antitumor activities primarily via repressing the expression of key proto-oncogenes, including c-Myc $(25,26)$. The expression of miR-22 is itself negatively regulated by c-Myc, creating a double negative feedback loop (27). Downregulation of miR-22 and/or overexpression of c-Myc are typically found in numerous cancer types (19-24,30), which indicates increased proliferation and inhibition of apoptosis. Imbalance of the cell proliferation/apoptosis ratio facilitates carcinogenesis (53) and serves a key role in the induction of chemo-resistance (38). To investigate the molecular mechanisms mediating the anti-chemo-resistance activity of PZH, the present study investigated its effect on cell proliferation and apoptosis. The results of colony formation assays and FACS analysis (with PI staining), demonstrated that PZH inhibited the proliferation of $5 \mathrm{HCT}-8 / 5-\mathrm{FU}$ cells via $\mathrm{G}_{1} / \mathrm{S}$ cell cycle arrest. In addition, Hoechst staining and colorimetric assays identified that PZH promoted the apoptosis of HCT-8/5-FU cells by activating caspase- 3 and caspase- 9 . Furthermore, data from RT-PCR, western blotting and RT-qPCR analyses indicated that PZH treatment markedly increased the expression of miR-22 and Bax, and decreased the expression of c-Myc, Bcl-2, cyclin D1 and CDK4 in a dose-dependent manner.

In conclusion, the present study demonstrates that PZH inhibited the proliferation of HCT-8/5-FU cells and promoted their apoptosis, primarily through modulating the miR-22/c-Myc network, which is a mechanism through which PZH overcomes cancer cell chemo-resistance.

\section{Acknowledgements}

This present study was supported by the National Natural Science Foundation of China (grant no. 81403390), the Research Fund of the Education Bureau of Fujian Province (grant no. JA14162), the Joint-Project of Education and Health Bureaus of Fujian Province (grant no. WKJ-FJ-21) and the Developmental Fund of Chen Keji Integrative Medicine (grant nos. CKJ2013012, CKJ2014004 and CKJ2015005).

\section{References}

1. Siegel R, Ma J, Zou Z and Jemal A: Cancer statistics, 2014. CA Cancer J Clin 64: 9-29, 2014.

2. Gustin DM and Brenner DE: Chemoprevention of colon cancer: Current status and future prospects. Cancer Metast Rev 421: 323-348, 2002.

3. De Rosa M, Pace U, Rega D, Costabile V, Duraturo F, Izzo P and Delrio P: Genetics, diagnosis and management of colorectal cancer (Review). Oncol Rep 34: 1087-1096, 2015. 
4. Gieseler F, Rudolph P, Kloeppel G and Foelsch UR: Resistance mechanisms of gastrointestinal cancers: Why does conventional chemotherapy fail? Int J Colorectal Dis 18: 470-480, 2003.

5. Tentes IK, Schmidt WM, Krupitza G, Steger GG, Mikulits W, Kortsaris A and Mader RM: Long-term persistence of acquired resistance to 5-fluorouracil in the colon cancer cell line SW620. Exp Cell Res 316: 3172-3181, 2010.

6. Van Cutsem E and Costa F: Progress in the adjuvant treatment of colon cancer: Has it influenced clinical practice? JAMA 294: 2758-2760, 2005.

7. Qi F, Zhao L, Zhou A, Zhang B, Li A, Wang Z and Han J: The advantages of using traditional Chinese medicine as an adjunctive therapy in the whole course of cancer treatment instead of only terminal stage of cancer. Biosci Trends 9: 16-34, 2015.

8. Yu C, Liu SL, Qi MH, Zou X, Wu J and Zhang J: Herbal medicine Guan Chang Fu Fang enhances 5-fluorouracil cytotoxicity and affects drug-associated genes in human colorectal carcinoma cells. Oncol Lett 9: 701-708, 2015.

9. Newman DJ, Cragg GM and Snader KM: The influence of natural products upon drug discovery. Nat Prod Rep 17: 215-234, 2000.

10. Gordaliza M: Natural products as leads to anticancer drugs. Clin Transl Oncol 9: 767-776, 2007

11. Valencia-Sachez MA, Liu J, Hannon GJ and Parker R: Control of translation and mRNA degradation by miRNAs and siRNAs. Genes Dev 20: 515-524, 2006.

12. Bagga $\mathrm{S}$ and Pasquinelli AE: Identification and analysis of microRNAs. Genet Eng (NY) 27: 1-20, 2006

13. Xuan Y, Yang H, Zhao L, Lau WB, Lau B, Ren N, Hu Y, Yi T, Zhao X, Zhou S and Wei Y: MicroRNAs in colorectal cancer: Small molecules with big functions. Cancer Lett 360: 89-105, 2015.

14. Tokarz P and Blasiak J: The role of microRNA in metastatic colorectal cancer and its significance in cancer prognosis and treatment. Acta Biochim Pol 59: 467-474, 2012.

15. Li H, Tang J, Lei H, Cai P, Zhu H, Li B, Xu X, Xia Y and Tang W: Decreased miR-200a/141 suppress cell migration and proliferation by targeting PTEN in Hirschsprung's disease. Cell Physiol Biochem 34: 543-553, 2014.

16. Zhang H, Tang J, Li C, Kong J, Wang J, Wu Y, Xu E and Lai M miR-22 regulates 5-FU sensitivity by inhibiting autophagy and promoting apoptosis in colorectal cancer cells. Cancer Lett 356 781-790, 2015

17. Chai J, Dong W, Xie C, Wang L, Han DL, Wang S, Guo HL and Zhang ZL: MicroRNA-494 sensitizes colon cancer cells to fluorouracil through regulation of DPYD. IUBMB Life 67: 191-3201, 2015.

18. He J, Xie G, Tong J, Peng Y, Huang H, Li J, Wang N and Liang H: Overexpression of microRNA-122 re-sensitizes 5-FU-resistan colon cancer cells to 5-FU through the inhibition of PKM2 in vitro and in vivo. Cell Biochem Biophys 70: 1343-1350, 2014.

19. Li J, Zhang Y, Zhao J, Kong F and Chen Y: Overexpression of miR-22 reverses paclitaxel-induced chemoresistance through activation of PTEN signaling in p53-mutated colon cancer cells. Mol Cell Biochem 357: 31-38, 2011.

20. Yamakuchi M, Yagi S, Ito T and Lowenstein CJ: MicroRNA-22 regulates hypoxia signaling in colon cancer cells. PLoS One 6: e20291, 2011

21. Zhang G, Xia S, Tian H, Liu Z and Zhou T: Clinical significance of miR-22 expression in patients with colorectal cancer. Med Oncol 29: 3108-3112, 2012

22. Tsuchiya $N$, Izumiya $M$, Ogata-Kawata $H$, Okamoto $K$, Fujiwara Y, Nakai M, Okabe A, Schetter AJ, Bowman ED, Midorikawa Y, et al: Tumor suppressor miR-22 determines p53-dependent cellular fate through post-transcriptional regulation of p21. Cancer Res 71: 4628-4239, 2011.

23. Guo S, Bai R, Liu W, Zhao A, Zhao Z, Wang Y, Wang Y, Zhao W and Wang W: miR-22 inhibits osteosarcoma cell proliferation and migration by targeting HMGB1 and inhibiting HMGB1-mediated autophagy. Tumour Biol 35: 7025-7034, 2014.

24. Li B, Song Y, Liu TJ, Cui YB, Jiang Y, Xie ZS and Xie SL: miRNA-22 suppresses colon cancer cell migration and invasion by inhibiting the expression of T-cell lymphoma invasion and metastasis 1 and matrix metalloproteinases 2 and 9. Oncol Rep 29: 1932-1938, 2013.

25. Bar N and Dikstein R: miR-22 forms a regulatory loop in PTEN/AKT pathway and modulates signaling kinetics. PLoS One 5: e10859, 2010.
26. Xiong J, Du Q and Liang Z: Tumor-suppressive microRNA-22 inhibits the transcription of E-box-containing c-Myc target genes by silencing c-Myc binding protein. Oncogene 29: 4980-4988, 2010.

27. Chang TC, Yu D, Lee YS, Wentzel EA, Arking DE, West KM, Dang CV, Thomas-Tikhonenko A and Mendell JT: Widespread microRNA repression by Myc contributes to tumorigenesis. Nat Genet 2008: 43-50, 2008

28. Zhao Q, Assimopoulou AN, Klauck SM, Damianakos H, Chinou I, Kretschmer N, Rios JL, Papageorgiou VP, Bauer R and Efferth T: Inhibition of c-MYC with involvement of ERK/JNK/MAPK and AKT pathways as a novel mechanism for shikonin and its derivatives in killing leukemia cells. Oncotarget 6: 38934-38951, 2015.

29. Kuo HY, Hsu HT, Chen YC, Chang YW, Liu FT and Wu CW: Galectin-3 modulates the EGFR signalling- mediated regulation of Sox2 expression via c-Myc in lung cancer. Glycobiology 26: $155-165,2016$.

30. Chen Y, McGee J, Chen X, Doman TN, Gong X, Zhang Y, Hamm N, Ma X, Higgs RE, Bhagwat SV, et al: Identification of druggable cancer driver genes amplified across TCGA datasets. PLoS One 9: e98293, 2014.

31. Dang CV, Resar LM, Emison E, Kim S, Li Q, Prescott JE, Wonsey D and Zeller K: Function of the c-Myc oncogenic transcription factor. Exp Cell Res 253: 63-77, 1999.

32. Hermeking H, Rago C, Schuhmacher M, Li Q, Barrett JF, Obaya AJ, O'Connell BC, Mateyak MK, Tam W, Kohlhuber F, et al: Identification of CDK4 as a target of c-MYC. Proc Natl Acad Sci USA 97: 2229-2234, 2000.

33. Wang WB, Yang Y, Zhao YP, Zhang TP, Liao Q and Shu H: Recent studies of 5-fluorouracil resistance in pancreatic cancer. World J Gastroenterol 20: 15682-15690, 2014.

34. Violette S, Poulain L, Dussaulx E, Pepin D, Faussat AM, Chambaz J, Lacorte JM, Staedel C and Lesuffleur T: Resistance of colon cancer cells to long-term 5-fluorouracil exposure is correlated to the relative level of $\mathrm{Bcl}-2$ and $\mathrm{Bcl}-\mathrm{X}(\mathrm{L})$ in addition to Bax and p53 status. Int J Cancer 98: 498-504, 2002.

35. Kugimiya N, Nishimoto A, Hosoyama T, Ueno K, Enoki T, Li TS and Hamano K: The c-MYC-ABCB5 axis plays a pivotal role in 5-fluorouracil resistance in human colon cancer cells. J Cell Mol Med 19: 1569-1581, 2015.

36. Chinese Pharmacopoeia Commission: Pharmacopoeia of the People's Republic of China. Vol 1.9th edition. Chinese Medical Science and Technology Press, Beijing, 2010.

37. Lin JM, Wei LH, Chen YQ, Liu XX, Hong ZF, Sferra TJ and Peng J: Pien Tze Huang-induced apoptosis in human colon cancer HT-29 cells is associated with regulation of the Bcl-2 family and activation of caspase-3. Chin J Integr Med 17: 685-690, 2011.

38. Zhuang Q, Hong F, Shen A, Zheng L, Zeng J, Lin W, Chen Y, Sferra TJ, Hong Z and Peng J: Pien Tze Huang inhibits tumor cell proliferation and promotes apoptosis via suppressing the STAT3 pathway in colorectal cancer mouse. Int J Oncol 40: 1569-1574, 2012.

39. Shen A, Hong F, Liu L, Lin JM, Zhuang QC, Hong ZF and Peng J: Effects of Pien Tze Huang on angiogenesis in vivo and in vitro. Chin J Integr Med 18: 431-436, 2012

40. Shen A, Hong F, Liu L, Lin J, Wei L, Cai Q, Hong Z and Peng J: Pien Tze Huang inhibits the proliferation of human colon carcinoma cells by arresting G1/S cell cycle progression. Oncol Lett 4: 767-770, 2012.

41. Shen A, Chen Y, Hong F, Lin J, Wei L, Hong Z, Sferra TJ and Peng J: Pien Tze Huang suppresses IL-6-inducible STAT3 activation in human colon carcinoma cells through induction of SOCS3. Oncol Rep 28: 2125-2130, 2012.

42. Shen A, Lin J, Chen Y, Lin W, Liu L, Hong Z, Sferra TJ and Peng J: Pien Tze Huang inhibits tumor angiogenesis in a mouse model of colorectal cancer via suppression of multiple cellular pathways. Oncol Rep 30: 1701-1706, 2013.

43. Lin W, Zhuang Q, Zheng L, Cao Z, Shen A, Li Q, Fu C, Feng J and Peng J: Pien Tze Huang inhibits liver metastasis by targeting TGF- $\beta$ signaling in an orthotopic model of colorectal cancer. Oncol Rep 33: 1922-1928, 2015.

44. Chen H, Shen A, Zhang Y, Chen Y, Lin J, Lin W, Sferra T and Peng J: Pien Tze Huang inhibits hypoxia-induced epithelial-mesenchymal transition in human colon carcinoma cells through suppression of the HIF-1 pathway. Exp Ther Med 7: 1237-1242, 2014

45. Shen A, Lin W, Chen Y, Liu L, Chen H, Zhuang Q, Lin J, Sferra TJ and Peng J: Pien Tze Huang inhibits metastasis of human colorectal carcinoma cells via modulation of TGF- $\beta 1 / \mathrm{ZEB} / \mathrm{miR}-200$ signaling network. Int J Oncol 46: 685-690, 2014. 
46. Chen H, Feng J, Zhang Y, Shen A, Chen Y, Lin J, Lin W, Sferra TJ and Peng J: Pien Tze Huang inhibits hypoxia-induced angiogenesis via HIF-1 $\alpha /$ VEGF-a pathway in colorectal cancer. Evid Based Complement Alternat Med 2015: 454279, 2015.

47. Shen A, Chen H, Chen Y, Lin J, Lin W, Liu L, Sferra TJ and Peng J: Pien Tze Hung overcomes multidrug resistance and epithelial-mesenchymal transition in human colorectal carcinoma cells via suppression of TGF- $\beta$ pathway. Evid Based Complement Alternat Med 2014: 679436, 2014.

48. Livak KJ and Schmittgen TD: Analysis of relative gene expression data using real-time quantitative PCR and the 2(-Delta DeltaC(T)) method. Methods 25: 402-408, 2001.

49. Longley DB, Allen WL and Johnston PG: Drug resistance, predictive markers and pharmacogenomics in colorectal cancer. Biochim Biophys Acta 1766: 184-196, 2006.
50. Lippman SM: The dilemma and promise of cancer chemoprevention. Nat Clin Pract Oncol 3: 523, 2006.

51. Fu Y, Zhang L, Hong Z, Zheng H, Li N, Gao H, Chen B and Zhao Y: Methanolic extract of Pien Tze Huang induces apoptosis signaling in human osteosarcoma MG63 Cells via multiple pathways. Molecules 21: 283, 2016.

52. He F, Wu HN, Cai MY, Li CP, Zhang X, Wan Q, Tang SB and Cheng JD: Inhibition of ovarian cancer cell proliferation by Pien Tze Huang via the AKT-mTOR pathway. Oncol Lett 7: 2047-2052, 2014.

53. Admas JM and Cory S: The Bcl-2 apoptotic switch in cancer development and therapy. Oncogene 26: 1324-1337, 2007. 